\begin{tabular}{|c|c|}
\hline 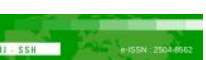 & Malaysian Journal of Social Sciences and Humanities (MJSSH) \\
\hline Malaysian Journal of & Volume 5, Issue 11, November 2020 \\
\hline (MJ-SSH) & e-ISSN : 2504-8562 \\
\hline & $\begin{array}{l}\text { Journal home page: } \\
\text { www.msocialsciences.com }\end{array}$ \\
\hline
\end{tabular}

\title{
Pembelajaran Terarah Kendiri dan Pengaruhnya terhadap Tanggapan Kebolehgajian Diri Pelajar Vokasional di Sabah
}

\author{
Asrin Gili1 , Abdul Said Ambotang 1 \\ ${ }^{1}$ Fakulti Psikologi dan Pendidikan, Universiti Malaysia Sabah (UMS) \\ Corrrespondence: Asrin Gili (egavriil2112@gmail.com)
}

\begin{abstract}
Abstrak
Kajian ini bertujuan mengenal pasti hubungan dan pengaruh Pembelajaran Terarah Kendiri (PTK) terhadap Tanggapan Kebolehgajian Diri (TKD) pelajar Kolej Vokasional (KV) di Sabah, Malaysia. Kajian kuantitatif yang mengaplikasikan kaedah tinjauan cross-sectional ini menggunakan satu set soal selidik adaptasi untuk memungut data daripada 297 orang pelajar semester akhir yang dipilih sebagai responden. Analisis deskriptif menunjukkan bahawa PTK dan TKD pelajar dipersepsi pada tahap tinggi. Analisis Korelasi Pearson pula mendapati bahawa terdapat hubungan yang signifikan, positif dan kuat antara PTK dan TKD pelajar. Sementara itu, analisis regresi mudah pula mendapati bahawa PTK mempunyai pengaruh yang signifikan dan merupakan peramal penting kepada TKD pelajar pada kadar $50.0 \%$. Dapatan-dapatan kajian ini ialah bukti empirikal bahawa TKD yang menjadikan pelajar lebih berkeyakinan untuk bersaing dalam pasaran buruh selepas menamatkan pengajian boleh ditingkatkan melalui pengupayaan PTK. Justeru, dapatan kajian ini diharap dapat dijadikan panduan kepada semua pihak yang terlibat secara langsung atau tidak langsung dalam sistem pendidikan KV dan juga penyelidikan dalam usaha meningkatkan kebolehgajian pelajar menerusi intervensi PTK.
\end{abstract}

Kata kunci: kebolehgajian, tanggapan kebolehgajian diri, pembelajaran terarah kendiri, vokasional

\section{Self-Directed in Learning and Its Influence on Self-Perceived Employability of Vocational Students in Sabah}

\begin{abstract}
This study aims to identify the relationship and influence of Self-Directed Learning (SDL) on the SelfPerceived Employability (SPE) of Vocational College (VC) students in Sabah, Malaysia. This quantitative study that apply cross-sectional survey method use a set of adapted questionnaires to collect data from the 297 final semester students as respondents. Descriptive analysis shows that SDL and SPE are perceived at a high level. Pearson Correlation Analysis found that there was a significant, positive and strong relationship between SDL and SPE. Meanwhile, simple regression analysis also found that SDL has a significant influence and is an important predictor of students' SPE at a rate of $50.0 \%$. The findings of this study are empirical evidence which suggest SPE that enables students to be more confident to compete in the labour market after graduation can be enhanced through the empowerment of SDL. Therefore, the findings of this study is intended to be a guide directly or indirectly to those involve in the VC education system as well as research in enhancing student employability through SDL intervention.
\end{abstract}


Keywords: employability, self-perceived employability, self-directed learning, vocational

\section{Pengenalan}

Modal insan yang unggul merupakan aset terpenting bagi pembangunan sesebuah negara. Tidak ada negara mampu mencapai kemajuan tanpa memiliki modal insan cemerlang yang berkemahiran tinggi, boleh bertindak balas dengan pantas secara kreatif terhadap perubahan ekonomi, serta berpaksikan penjanaan dan penggunaan pengetahuan secara optimum. Dalam hal ini, pendidikan secara berterusan ialah kunci yang utama. Satu daripada impak penting pendidikan terhadap modal insan adalah pembangunan kebolehgajian yang mampan dalam kalangan pelajar dan graduan (Donald, Baruch \& Asleigh, 2017). Menurut Fugate, Kinicki dan Ashforth (2004), kebolehgajian ialah faktor kritikal yang menentukan peluang dan daya saing seseorang individu dalam pasaran buruh. Justeru, semua institusi pendidikan terutamanya di peringkat tinggi dituntut agar terus konsisten dalam melahirkan graduan yang mempunyai tahap kebolehgajian yang tinggi sejajar dengan keperluan dan kehendak pasaran buruh yang sentiasa berubah kesan daripada kerancakan percambahan teknologi dan arus globalisasi pada hari ini.

Kebolehgajian pelajar dan graduan merupakan agenda yang semakin mendapat perhatian bukan sahaja di Malaysia tetapi juga di peringkat global. Ini kerana isu kebolehgajian sering dikaitkan dengan masalah pengangguran terutamanya dalam kalangan graduan yang semakin membimbangkan sejak kebelakangan ini. Berdasarkan laporan International Labour Organisastion - ILO (2015), kadar pengangguran global pada tahun 2015 telah mencecah $13.1 \%$ dengan anggaran 71 juta belia menganggur (ILO, 2016). Di Malaysia, kadar pengangguran turut meningkat sebanyak $0.4 \%$ iaitu daripada $2.9 \%$ pada tahun 2014 kepada 3.4\% pada tahun 2017 (Jabatan Perangkaan Malaysia, 2018). Pengangguran di Malaysia sebahagian besar melibatkan belia yang berusia 15 hingga 24 tahun (Ibrahim \& Mahyuddin, 2017), yang majoritinya ialah graduan baharu. Dianggarkan lebih 200,000 orang graduan dikeluarkan setiap tahun namun statistik mendedahkan bahawa sekurang-kurangnya satu daripada setiap empat graduan ini gagal mendapatkan pekerjaan dalam tempoh enam bulan selepas tamat pengajian (Leo, 2018). Laporan Pengesanan Graduan pula melaporkan masing-masing 22.7\%, 20.9\% dan $19.8 \%$ graduan masih menganggur pada tahun 2016, 2017 dan 2018 (KPM, 2018; 2019). Secara khusus di Sabah pula, laporan sama mendedahkan kadar pengangguran di negeri ini ialah 31.4\% pada tahun 2017 dan $31.0 \%$ pada tahun berikutnya, dan merupakan yang tertinggi di Malaysia.

Berdasarkan laporan statistik ini, jelas bahawa fenomena pengangguran terutamanya dalam kalangan graduan perlu diberi perhatian wajar kerana golongan ini merupakan aset modal insan yang menentukan maju mundur negara (Kassim, 2020). Kegagalan menangani isu ini sudah pasti akan menghalang impian negara untuk mencapai status negara maju dan berpendapatan tinggi, bahkan dikhuatiri mencetuskan gejala negatif lain seperti masalah kesihatan mental dan keruntuhan institusi keluarga yang disebabkan oleh tekanan hidup, serta aktiviti jenayah yang didorong oleh desakan akibat tiada sokongan kewangan (Law, 2018; Bahrim et al., 2019). Menyedari hakikat ini, mengenal pasti punca masalah perlu segera dilakukan supaya intervensi terbaik dapat dirancang dan seterusnya dilaksanakan. Seperti dijelaskan sebelum ini, isu kebolehgajian pelajar yang rendah sering dikaitkan dengan permasalahan pengangguran ini di Malaysia (Zaliza \& Safarin, 2014; Yusof, Nooriah \& Jamaludin, 2015; Law, 2018; Leo, 2018; Cheng \& Mohamad, 2020). Justeru, kajian tentang kebolehgajian pelajar dan faktor yang mempengaruhinya adalah penting.

Dalam kajian ini, isu kebolehgajian yang menjadi fokus utama adalah dari perspektif individu pelajar iaitu Tanggapan Kebolehgajian Diri (TKD) pelajar. Secara ringkas, TKD dalam kajian ini didefinisikan sebagai 'persepsi pelajar tentang kemungkinan dan keupayaannya untuk mendapat pekerjaan yang sesuai dengan kelayakan yang dimiliki selepas menamatkan pengajian' (Rothwell et al., 2018). TKD ialah konsep yang penting kerana menurut Teori Sosial Bandura, kecenderungan seseorang individu untuk bertindak lebih ditentukan oleh persepsinya berbanding apapun realiti objektif (Berntson \& Marklund, 2007; De Cuyper et al., 2008; Emmerik et al., 2012). Lo Presti dan Pluviano (2016) mengartikulasikan persepsi individu adalah lebih penting berbanding situasi objektif kerana persepsi yang tepat 
mencetuskan sikap dan tingkah laku yang lebih adaptif. Hujahnya, persepsi terhadap situasi mampu mempengaruhi tingkah laku, tindak balas, dan pemikiran seseorang. Oleh itu, seseorang individu dengan TKD yang tinggi dilihat lebih berpeluang untuk berjaya mendapat pekerjaan dan sebaliknya.

TKD seseorang pelajar dibentuk oleh banyak faktor, namun pengalaman pendidikan dan pembelajaran dikenal pasti sebagai penentu utama khususnya dalam konteks pelajar atau graduan. Pembelajaran Terarah Kendiri (PTK) merupakan satu daripada faktor yang dilihat mempunyai kaitan dengan pembangunan TKD pelajar. PTK berperanan penting dalam mengekalkan kebolehgajian dan daya saing individu dalam pasaran buruh (Francom, 2010; Raemdonck et al., 2012) dan sangat membantu pelajar dan graduan untuk beradaptasi dan menangani perubahan pesat dalam persekitaran sosial, fizikal, serta dalam pekerjaan (Ramsey \& Couch, 1994; O’Donoghue \& Maguire, 2005; Raemdonck, Gijbels, \& Van Groen, 2014). Dalam literatur, beberapa kajian lain turut mendedahkan hubungan antara tingkah laku PTK dengan TKD pelajar (Botha, 2012; Botha et al., 2015; Kim et al., 2015; Kim \& Kim, 2018; Khong, 2018).

Hubungan teoretikal antara PTK dan TKD juga dapat diperhatikan dalam Teori Modal Insan dalam pendidikan gagasan Donald et al. (2017) yang menjelaskan bahawa TKD pelajar dapat dibangunkan menerusi enam jenis modal insan yang sepatutnya diperoleh di institusi pengajian iaitu modal kemahiran, modal skolastik, modal budaya, modal sosial, modal psikologi (nilai dalaman) dan modal nilai pasaran. Perkaitan teoritikal dapat dilihat menerusi peranan PTK yang bukan sahaja dapat mengukuhkan modal budaya menerusi elemen media sosial, tetapi juga mengukuhkan modal psikologi atau nilai dalaman pelajar. Modal psikologi menurut Baruch et al. (2005) merangkumi personaliti pelajar yang proaktif, kesedaran diri, keyakinan, harapan, optimisme dan keyakinan diri yang tinggi. Atribut-atribut peribadi dalam modal psikologi ini selari dengan atribut yang dimiliki oleh individu yang memiliki PTK yang tinggi.

Berdasarkan pendedahan literatur ini, jelas bahawa PTK merupakan elemen yang cukup berperanan dalam memastikan kebolehgajian pelajar terutamanya di peringkat pengajian tinggi. Justeru itu, kajian ini diinisiatifkan untuk mengkaji dan memahami dengan lebih mendalam bagaimana elemen ini berhubungan dan berpengaruh terhadap TKD khususnya dalam kalangan pelajar Kolej Vokasional (KV) di Sabah dan amnya di Malaysia. Dalam konteks pendidikan KV yang secara relatifnya masih baharu, pemahaman mendalam tentang PTK dan TKD adalah penting sebagai satu daripada usaha untuk mencari penyelesaian kepada masalah pengangguran dalam kalangan graduan KV. Berdasarkan Laporan Pengesanan Graduan 2018 (KPM, 2019), seramai 22.4\% daripada graduan KV dilaporkan masih belum bekerja pada tahun 2018. Peratusan ini jauh lebih tinggi jika dibandingkan dengan graduan daripada Politeknik (3,9\%) dan Kolej Komuniti (3.4\%) yang mempunyai fungsi sama menghasilkan graduan vokasional di peringkat sijil dan diploma. Laporan statistik ini memberi gambaran jelas bahawa kajian tentang kebolehgajian dan faktor yang mempengaruhinya adalah perlu bagi mengenal pasti punca serta alternatif kepada permasalahan ini. Jika tidak ditangani dengan baik, ia dikhuatiri memberi kesan kepada pelajar KV sehingga mereka gagal dalam persaingan dalam pasaran buruh seperti yang diharapkan. Jika graduan yang dihasilkan tidak boleh memenuhi pasaran buruh, maka sistem pendidikan itu dikatakan telah gagal. Kajian ini diharap dapat membantu para pemegang taruh KV di semua peringkat dalam menambah baik program pendidikan sekali gus memastikan matlamat serta objektif untuk meningkatkan kebolehgajian pelajar dapat dicapai dengan cemerlang melalui intervensi PTK.

\section{Tujuan dan Objektif Kajian}

Kajian ini bertujuan mengenal pasti hubungan serta pengaruh pembelajaran terarah kendiri terhadap tanggapan kebolehgajian diri pelajar kolej vokasional di negeri Sabah, Malaysia. Selaras dengan tujuan ini, objektif khusus kajian ini ialah:

(i) Mengkaji tahap pembelajaran terarah kendiri (PTK) dan tanggapan kebolehgajian diri (TKD) pelajar. 
(ii) Mengenal pasti hubungan antara pembelajaran terarah kendiri (PTK) dengan tanggapan kebolehgajian diri (TKD) pelajar.

(iii) Mengenal pasti pengaruh pembelajaran terarah kendiri (PTK) terhadap tanggapan kebolehgajian diri (TKD) pelajar.

\section{Hipotesis Kajian}

Berpandukan objektif kajian, dua hipotesis nul berikut telah dibina untuk diuji:

$\mathrm{Ho}^{1}$ : Tidak terdapat hubungan yang signifikan antara pembelajaran terarah kendiri (PTK) dengan tanggapan kebolehgajian diri (TKD) pelajar.

$\mathrm{Ho}^{2}$ : $\quad$ Tidak terdapat pengaruh yang signifikan pembelajaran terarah kendiri (PTK) terhadap tanggapan kebolehgajian diri (TKD) pelajar.

\section{Tinjauan Literatur}

\section{Tanggapan Kebolehgajian Diri}

Kebanyakan kajian tentang kebolehgajian bertumpu kepada tiga perspektif iaitu individu, organisasi dan majikan, dan pendidikan dan kerajaan (Thijssen et al., 2008; Guilbert et al. 2016). Namun dalam kajian ini, fokus utama adalah kebolehgajian dari perspektif individu yang berkaitan dengan persepsi atau tanggapan pelajar terhadap peluang mereka untuk mendapatkan pekerjaan, yang juga dirujuk sebagai Tanggapan Kebolehgajian Diri (TKD). Menurut Bernston dan Marklund (2007), TKD didefinisikan sebagai 'persepsi individu tentang kebarangkalian atau kemungkinannya untuk mendapat pekerjaan'. Selari dengan definisi ini, Vanherker et al. (2014) mengartikulasikan TKD sebagai 'persepsi individu tentang kemungkinannya mendapatkan dan mengekalkan pekerjaan'. Masih pada jajaran sama, Veld et al. (2015) menambah bahawa TKD ialah persepsi seseorang tentang kemungkinannya mendapat pekerjaan dalam pasaran buruh dalaman dan luaran.

Dari perspektif individu pelajar, Rothwell et al. (2008) pula mendefinisikan TKD sebagai tanggapan atau persepsi seseorang pelajar tentang keupayaannya mendapatkan pekerjaan tetap yang sesuai dengan kelayakan yang dimiliki. Rothwell et al. (2008) menerusi Model Students' Self-Perceived Employability (SSPE) yang dibangunkannya menjelaskan bahawa TKD pelajar dan graduan ditentukan oleh dua faktor utama iaitu kebolehgajian dalaman dan kebolehgajian luaran. Kebolehgajian dalaman merujuk kepada persepi pelajar terhadap keupayaan dalaman, kemahiran dan prestasi akademik, serta keupayaan mencari pekerjaan, sementara kebolehgajian luaran pula adalah berkaitan dengan faktor psikososial lain seperti keadaan pasaran buruh, reputasi institusi pengajian, dan permintaan bidang pengajian dalam pasaran buruh (Rothwell et al., 2008).

Kesimpulannya, TKD mengambil berat tentang persepsi individu mengenai kemungkinannya untuk mendapatkan atau mengekalkan pekerjaan dalam pasaran buruh dalaman dan juga luaran. Andaiannya adalah seseorang individu yang mempunyai tahap TKD yang tinggi adalah lebih berpeluang untuk mendapat pekerjaan. Menurut Roskies dan Louis-Guerin (1990), persepsi diri sangat menentukan kebolehgajian individu kerana seperti yang dijelaskan oleh Teori Sosial Bandura, seseorang individu dilihat lebih cenderung bertindak sesuai dengan persepsi berbanding realiti objektif apa pun (De Cuyper et al., 2008; Emmerik et al., 2012). Beberapa kajian lepas (Bernston \& Marklund, 2007; Kim et al., 2015) turut menyokong hujah ini apabila mendapati bahawa TKD merupakan peramal yang lebih baik dalam menilai sikap, niat serta kesejahteraan psikologi pekerja berbanding kebolehgajian objektif. Justeru, berdasarkan literatur ini, hujah utama yang cuba diketengahkan dalam kajian ini adalah seseorang individu pelajar yang memiliki TKD tinggi bukan sahaja lebih percaya diri, bahkan mereka juga akan bertindak lebih proaktif sehingga memudahkan mereka mendapat pekerjaan selepas menamatkan pengajian. 


\section{Pembelajaran Terarah Kendiri}

Peranan konsep Pembelajaran Terarah Kendiri (PTK) dalam teori dan amalan pembelajaran dasawarsa ini semakin penting, bahkan elemen PTK juga dilihat cukup memberi impak kepada kejayaan seseorang pelajar. Kesepaduan aspek pengajaran dan bimbingan yang berkesan, disertai dengan motivasi dan pengupayaan PTK pelajar menyumbang kepada pembangunan modal insan seperti yang diaspirasikan dalam Falsafah Pendidikan Kebangsaan di Malaysia (Taat \& Abdullah, 2014). Menurut Knowles (1975), PTK dapat didefinisikan sebagai 'proses yang mana individu mengambil inisiatif, dengan atau tanpa bantuan orang lain, untuk mendiagnosis keperluan pembelajaran, mengatur matlamat pembelajaran, mengenal pasti sumber dan bahan pembelajaran, memilih dan melaksanakan strategi pembelajaran yang sesuai, serta menilai hasil pembelajaran sendiri'. Definisi Knowles ini memberi penekanan pada elemen inisiatif yang diambil oleh individu dalam menentukan proses dan hasil pembelajaran. Selari dengan Knowles, Brockett (1983) pula mentakrifkan PTK sebagai 'aktiviti yang mana tanggungjawab utama dalam merancang, menjalankan, dan menilai usaha pembelajaran ditanggapi oleh individu pelajar sendiri'.

Seiring dengan perkembangan konsep PTK, Brockett dan Hiemstra (1991) melihat keperluan untuk mempertimbangkan ciri-ciri atau faktor keperibadian pelajar dalam mendefinisikan konstruk ini. Justeru, dalam Model Personal Responsibility Orientation of Self-Direction in Learning (PRO-SDL) yang mereka bangunkan, PTK adalah melibatkan dua komponen yang berbeza namun berkaitan iaitu ciri proses pengajaran dan pembelajaran dan ciri dalaman atau keperibadian pelajar. Lebih spesifik, Brockett dan Hiemstra (1991) mentakrifkan PTK sebagai 'aktiviti yang mana tanggungjawab utama dalam merancang, menjalankan, dan menilai usaha pembelajaran ditanggapi oleh individu pelajar sendiri' dan merupakan gabungan kedua-dua 'ciri luaran iaitu proses pengajaran dan pembelajaran (inisiatif, kawalan)' dan 'ciri dalaman pelajar (efikasi diri, motivasi). Dalam kajian ini, definisi serta Model PRO-SDL oleh Brockett dan Heimstra (1991) digunakan sebagai landasan utama bagi mengoperasikan PTK.

Selaras dengan objektif kajian, tinjauan terhadap beberapa kajian lepas berkaitan PTK dan hubungan dengan kebolehgajian diri pelajar telah dijalankan. Kajian Lee, Tsai, Chai dan Koh (2014) dan Sulasiwi, Handayanto dan Wartono (2019) yang masing-masing dijalankan di Singapura dan Indonesia adalah kajian yang mendapati bahawa tahap PTK dalam kalangan pelajar adalah tinggi. Begitu juga, tahap PTK pelajar adalah tinggi dalam kajian Premkumar, Vinod, Satishkumar dan Arends (2018), dan Kidane, Roebertsen dan Van Der Vleuten (2020). Kedua-dua kajian ini turut merumuskan bahawa tahap PTK pelajar adalah seiring dengan tempoh pengajian dan mengesahkan bahawa sokongan tenaga pengajar khususnya dalam memberi bimbingan, galakan serta bantuan adalah cukup penting untuk memupuk dan meningkatkan tahap keupayaan PTK pelajar. Memperoleh dapatan berbeza, kajian Taqipour, Abbasi, Naeimi, Gaguly dan Miandasthi (2016) dan Tohidi (2019) pula merumuskan PTK pelajar berada pada tahap sederhana sahaja. Demikian juga, tahap PTK yang sederhana turut diperoleh Chou (2012) namun berjaya membuktikan bahawa elemen inisiatif, kawalan, motivasi dan efikasi diri yang ditekankan dalam Model PRO-SDL (Brockett \& Heimstra, 1991) sebagai penentu tahap PTK secara keseluruhan.

Dari aspek hubungan dan pengaruh PTK terhadap TKD, kajian Khong (2018) mendapati bahawa terhadap hubungan positif antara kedua-dua variabel ini. PTK dalam Khong (2018) turut membuktikan pengaruhnya yang signifikan terhadap TKD pelajar sungguhpun hanya pada aras sederhana sahaja. Analisis regresi yang dijalankan juga mendedahkan keempat-empat komponan PTK (inisiatif, kawalan, efikasi diri, motivasi) dapat menerangkan $18 \%$ varians TKD pelajar. Dapatan senada turut diperoleh Botha et al. (2015) apabila mendapati PTK berhubungan langsung dengan atribut kebolehgajian pelajar seperti keyakinan diri, kompetensi budaya, efikasi diri, kemampuan kerjaya, kebolehan sosial, orientasi sosial, proaktiviti dan juga literasi sosial yang dilihat mampu meningkatkan TKD pelajar. Tinjauan literatur juga mendapati hubungan positif antara TKD dengan angkubah-angkubah yang setara dengan PTK seperti tingkah laku pembelajaran sukarela (Gijbels et al., 2010) dan kesediaan untuk belajar (Wittekind et al, 2010). Sungguhpun kebanyakan kajian lepas menyimpulkan hubungan dan pengaruh yang signifikan, namun dapatan Kim et al. (2015) pula tampil berbeza. Kim et al. (2015) mendedahkan bahawa sungguhpun wujud hubungan antara tingkah laku pembelajaran sukarela dengan TKD pelajar, 
namun tidak terdapat bukti secara statistik untuk membuktikan pengaruh. Justeru, mereka merumuskan bahawa tingkah laku pembelajaran sukarela bukanlah peramal kepada kebolehgajian pelajar.

\section{Metod Kajian}

Selaras dengan matlamat untuk meningkatkan pemahaman tentang TKD pelajar yang dikaitkan dengan faktor-faktor terpilih, maka kajian yang berbentuk konvensional ini telah mengaplikasikan pendekatan kuantitatif dan dijalankan menggunakan kaedah tinjauan cross-sectional serta melibatkan analisis deskriptif dan analisis inferensi bagi mencapai objektif kajian. Populasi kajian ini ialah pelajar semester akhir di tujuh buah Kolej Vokasional di Sabah pada tahun 2019 melibatkan 1,143 orang pelajar. Kumpulan pelajar ini telah memulakan pengajian pada Januari 2015 dan tamat pada penghujung 2019 setelah melepasi semua syarat yang ditetapkan. Bagi pemilihan sampel pula, kajian ini menggunakan panduan popular Krejcie dan Morgan (1970). Berdasarkan panduan pensampelan ini, sampel minimum kajian ini ialah 288 orang. Walau bagaimanapun, kajian ini telah memperoleh sampel sebanyak 297 orang pelajar, jauh melebihi sasaran minimum yang dicadangkan.

Dari aspek pemungutan data, kajian ini telah menggunakan instrumen borang soal selidik berstruktur yang diadaptasi daripada beberapa pengkaji sebelum ini yang bersesuaian dengan objektif kajian. TKD diukur menggunakan Student's Self-Perceived Employability Scale (SSPES) oleh Rothwell et al. (2008) yang terdiri daripada 16 item dan melibatkan dua komponen iaitu kebolehgajian dalaman (6 item) dan kebolehgajian luaran (10 item). Sementara itu, Personal Responsibility Orientation of Self-Direction in Learning Scale (PRO-SDLS) oleh Stockdale dan Brockett (2011) pula digunakan untuk mengukur PTK. Soal selidik PRO-SDLS mempunyai 25 item dan melibatkan empat komponen iaitu motivasi (7 item), kawalan (6 item), inisiatif ( 6 item) dan efikasi diri (6 item). Maklum balas responden bagi setiap item dalam soal selidik ini menggunakan skala Likert 10-mata.

Kedua-dua instrumen yang digunakan dalam kajian ini juga telah disahkan mempunyai kesahan yang tinggi menerusi prosedur kesahan muka, kesahan kandungan dan kesahan konstruk melalui Analisis Faktor Penerokaan (EFA) yang ketat. Demikian juga, instrumen terbukti mempunyai kebolehpercayaan yang munasabah berdasarkan hasil ujian kebolehpercayaan yang dijalankan. Nilai alpha cronbach bagi instrumen tanggapan kebolehgajian diri ialah 0.943 dalam kajian rintis, manakala 0.986 dalam kajian sebenar. Nilai alpha cronbach bagi instrumen pembelajaran terarah kendiri pula masing-masing 0.962 dan 0.948 dalam kajian rintis dan kajian sebenar.

\section{Kerangka Konseptual Kajian}

\begin{tabular}{|c|c|}
\hline $\begin{array}{c}\text { Pembelajaran Terarah Kendiri } \\
\bullet \quad \text { Inisiatif }\end{array}$ & Kebolehgajian Pelajar \\
\hline $\begin{array}{l}\text { - } \quad \text { Kawalan } \\
\text { - } \quad \text { Efikasi Diri } \\
\text { - Motivasi } \\
\quad \text { Model PRO-SDL (Brockett \& Heimstra, } \\
\quad 1991 ; 2012)\end{array}$ & $\begin{array}{ll}-\quad & \text { Kebolehgajian Dalaman } \\
- & \text { Kebolehgajian Luaran } \\
& \text { Model SSPE (Rothwell et al., 2008) }\end{array}$ \\
\hline
\end{tabular}

\section{Dapatan Kajian}

\section{Tahap Pembelajaran Terarah Kendiri dan Tanggapan Kebolehgajian Diri Pelajar}

Pengukur tahap PTK dan TKD pelajar dalam kajian ini adalah berdasarkan empat tahap skor min iaitu 'rendah' ( $\min =1.0-3.9)$, 'sederhana' (min=4.0-5.9), 'tinggi' ( $\min =6.0-7.9)$ dan 'sangat tinggi' ( $\mathrm{min}=8.0$ 10.0). Dapatan analisis skor min yang diperoleh ditunjukkan dalam Jadual 1. 
DOI: https://doi.org/10.47405/mjssh.v5i11.560

Jadual 1: Tahap Pembelajaran Terarah Kendiri dan Tanggapan Kebolehgajian Diri Pelajar

\begin{tabular}{llll}
\hline Variabel & $\boldsymbol{N}$ & Min & SP \\
\hline Pembelajaran Terarah Kendiri (PTK) & $\mathbf{2 9 7}$ & $\mathbf{6 . 9 8 7}$ & $\mathbf{1 . 1 4 1}$ \\
- Inisiatif & & 6.868 & 1.465 \\
- Kawalan & & 7.036 & 1.438 \\
- Motivasi & & 7.018 & 1.428 \\
- Efikasi Diri & & 7.036 & 1.481 \\
& & & \\
Tanggapan Kebolehgajian Diri (TKD) & $\mathbf{2 9 7}$ & $\mathbf{6 . 6 1 0}$ & $\mathbf{1 . 3 4 2}$ \\
- Kebolehgajian Dalaman & & 6.936 & 1.332 \\
- Kebolehgajian Luaran & & 6.365 & 1.460 \\
& & &
\end{tabular}

Berdasarkan Jadual 1, analisis menunjukkan bahawa skor min PTK pada keseluruhannya ialah 6.987, sekali gus menyimpulkan bahawa tahap PTK pelajar adalah tinggi. Keempat-empat komponen yang mengukur PTK iaitu inisiatif ( $\min =6.868)$, kawalan $(\min =7.036)$, motivasi $(\min =7.018)$, dan efikasi diri $(\min =7.036)$ juga berada pada tahap tinggi. Demikian juga, tahap TKD pelajar pada keseluruhannya dapat disimpulkan berada pada tahap tinggi berdasarkan nilai skor min, 6.610 yang diperoleh. Komponen kebolehgajian dalaman $(\min =6.936)$ dan kebolehgajian luaran $(\min =6.369)$ yang mengukur TKD keseluruhan juga berada pada tahap tinggi.

\section{Ho1: Tidak Terdapat Hubungan Yang Signifikan Antara Pembelajaran Terarah Kendiri Dengan Tanggapan Kebolehgajian Diri Pelajar}

Hipotesis Nul $1\left(\mathrm{Ho}^{1}\right)$ telah diuji menggunakan Analisis Korelasi Pearson. Aras signifikan yang ditetapkan adalah $p<0.05$, sementara kekuatan hubungan pula ditentukan berdasarkan indeks korelasi yang dicadangkan Cohen et al. (2007) iaitu 'sangat kuat' ( $r=0.81-1.00)$, 'kuat' $(r=0.61-0.80)$, 'sederhana' ( $r=0.41-0.60)$, 'lemah' $(r=0.21-0.40)$, dan 'sangat lemah atau boleh diabaikan' $(r=0.01-0.20)$. Hasil analisis yang diperoleh adalah seperti pada Jadual 2.

Jadual 2: Analisis Korelasi Pearson Pembelajaran Terarah Kendiri Dengan Tanggapan Kebolehgajian Diri Pelajar

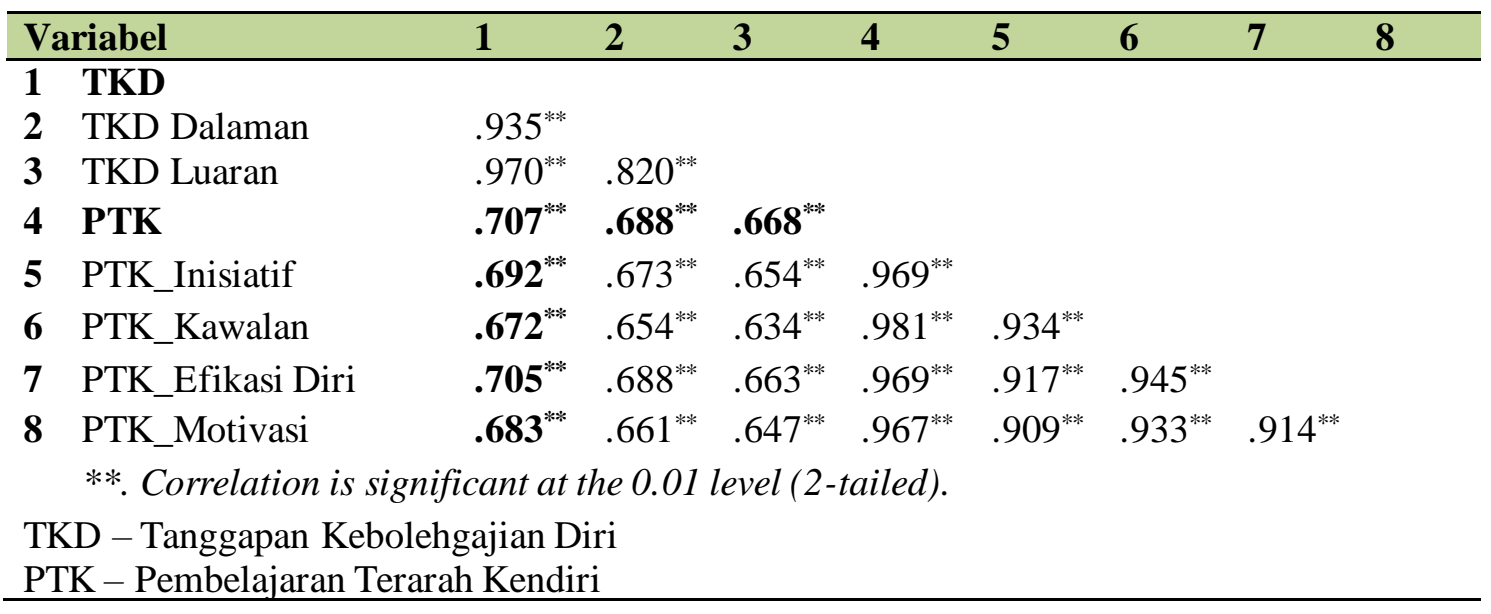

Berdasarkan Jadual 2, hasil analisis menunjukkan bahawa wujud hubungan yang positif dan signifikan $(r=0.707, p<0.01)$ antara PTK dengan TKD pelajar. Nilai pekali korelasi, $r=0.707$ yang diperoleh menjelaskan hubungan antara kedua-dua variabel ini adalah kuat. Selain itu, hasil analisis ini juga menunjukkan bahawa keempat-empat komponen PTK iaitu inisiatif $(r=0.692, p<0.01)$, kawalan $(r=0.672$, $p<0.01)$, efikasi diri $(r=0.705, p<0.01)$, dan motivasi $(r=0.683, p<0.01)$ masing-masing mempunyai hubungan yang signifikan dan positif dengan TKD pada kadar kuat. Begitu juga, PTK didapati mempunyai hubungan yang positif pada aras kuat dengan kedua-dua komponen TKD iaitu kebolehgajian 
dalaman $(r=0.688, p<0.01)$ dan kebolehgajian luaran $(r=0.668, p<0.01)$. Daripada dapatan analisis ini, jelas bahawa terdapat bukti yang kukuh untuk menolak Hipotesis $\mathrm{Nul} 1\left(\mathrm{Ho}^{1}\right)$. Oleh itu, dapat disimpulkan bahawa terdapat hubungan yang signifikan secara positif dan kuat antara PTK dengan TKD pelajar. Ini bermakna bahawa apabila PTK meningkat, maka TKD pelajar juga akan meningkat.

\section{$\mathrm{Ho}^{2}$ : Tidak Terdapat Pengaruh Yang Signifikan Pembelajaran Terarah Kendiri Terhadap Tanggapan Kebolehgajian Diri Pelajar}

Hipotesis Nul $2\left(\mathrm{Ho}^{2}\right)$ telah diuji menggunakan Analisis Regresi Mudah bagi menentukan pengaruh PTK sebagai variabel peramal terhadap TKD. Aras signifikan yang ditetapkan adalah $p<0.05$. Dapatan analisis ditunjukkan seperti pada Jadual 3.

Jadual 3: Analisis Regresi Pengaruh Pembelajaran Terarah Kendiri Terhadap Tanggapan Kebolehgajian Diri Pelajar

\begin{tabular}{llll}
\hline Variabel Peramal & $\boldsymbol{\beta}$ & $\boldsymbol{t}$ & $\boldsymbol{P}($ Sig. $)$ \\
\hline Pembelajaran Terarah Kendiri (PTK) & .707 & 17.191 & .000 \\
& & & \\
Maklumat: & & & \\
Pembelajaran Terarah Kendiri (PTK) & & & \\
$\mathrm{R}^{2} \quad=.500$ & & & \\
$\Delta \mathrm{R}^{2}=.500$ & & \\
$\mathrm{~F} \quad=295.545$ & & \\
\hline
\end{tabular}

Merujuk Jadual 3, nilai koefisien beta $(\beta)$ menunjukkan bahawa peningkatan 1 unit variabel PTK akan meningkatkan varians TKD sebanyak 0.707 unit $(\beta=0.707, t=17.191, p<0.001)$. Nilai $R^{2}$ yang diperoleh pula menjelaskan bahawa PTK dapat meramal TKD pelajar sebanyak 50.0\% $\left(R^{2}=0.500\right)$. Ini bermakna bahawa 50\% daripada varians dalam TKD dapat diterangkan oleh PTK, sementara 50\% lagi diterangkan oleh faktor-faktor lain yang tidak dikaji dalam kajian ini. Memandangkan nilai- $P$ dalam analisis ini adalah kurang daripada $p<0.05$, maka Hipotesis $\mathrm{Nul} 2\left(\mathrm{Ho}^{2}\right)$ berjaya ditolak. Justeru, terdapat bukti kukuh untuk menyimpulkan bahawa terdapat pengaruh yang signifikan bagi PTK terhadap TKD pelajar.

\section{Perbincangan Kajian}

PTK memainkan peranan penting dalam teori serta amalan pembelajaran kerana elemen ini membawa kesan kepada kejayaan seseorang pelajar, sekali gus menyumbang kepada pembangunan modal insan seperti yang diharapkan dalam Falsafah Pendidikan Kebangsaan di Malaysia (Taat \& Abdullah, 2014). Menurut Brockett \& Hiemstra (1991), PTK dipengaruhi oleh proses atau kaedah pembelajaran dan juga ciri-ciri keperibadian seseorang individu. Kajian ini mendapati pelajar KV di Sabah mempersepsi diri mereka memiliki tahap PTK yang tinggi. Empat elemen yang menentukan PTK secara keseluruhan iaitu kawalan, inisiatif, motivasi dan efikasi diri juga dipersepsi pada tahap tinggi.

Dapatan ini menggambarkan bahawa pelajar memiliki orientasi tanggungjawab peribadi yang tinggi berkaitan dengan pembelajaran, lebih proaktif serta berkebolehan merancang, melaksana, menilai, dan mengawal proses pembelajaran sendiri. Dapatan ini sejajar dengan beberapa kajian sebelum ini yang juga menunjukkan tahap PTK pelajar adalah tinggi (Lee et al., 2014; Khong, 2018; Sulasiwi et al., 20019). Menyokong Curran et al. (2019), tahap PTK yang tinggi dalam kajian ini mungkin dirangsang oleh penggunaan dan ketersediaan teknologi yang semakin canggih pada hari ini. Capaian internet yang semakin baik, media sosial dan penggunaan telefon pintar misalnya dibuktikan mempunyai hubungan positif kepada orientasi PTK pelajar (Rashid \& Asghar, 2016). Sungguhpun begitu, dapatan kajian ini bercanggah dengan Chou (2012) dan Tohidi (2019) yang mendapati tahap PTK dalam kalangan pelajar hanyalah pada tahap sederhana. Percanggahan dapatan ini walau bagaimanapun mungkin disebabkan oleh beberapa faktor misalnya heterogeniti budaya, persekitaran pembelajaran, galakan atau rangsangan pengajar, serta sokongan keluarga (Premkumar et al., 2018). 
Kajian ini menyimpulkan TKD pelajar juga berada pada tahap tinggi. Ini menjelaskan bahawa pelajar kolej vokasional mempunyai keyakinan tinggi bahawa mereka akan berjaya mendapat pekerjaan yang sepadan dengan kelayakannya selepas menamatkan pengajian. Keyakinan tinggi ini adalah hasil daripada persepsi yang baik terhadap kedua-dua faktor TKD (kebolehgajian dalaman dan kebolehgajian luaran). Berdasarkan dapatan ini, jelas bahawa pelajar mempunyai tanggapan positif terhadap kemahiran dan keupayaan dalaman, prestasi akademik serta kebolehan mencari pekerjaan yang dimiliki. Pada masa sama, mereka juga positif terhadap situasi semasa pasaran buruh, reputasi kolej dan permintaan pihak industri terhadap bidang pengajian yang diikuti. Tahap TKD yang tinggi dalam kajian ini adalah selari dengan Qenani et al. (2014) dan Coetzee dan Engelbrecht (2019) yang juga menunjukkan dapatan serupa. Sungguhpun demikian, kajian ini berkontra pula dengan Chun (2016), Huang (2016) dan Magnano et al. (2019) yang melaporkan tahap TKD hanya pada tahap sederhana. Dapatan yang bercanggahan ini adalah wajar kerana TKD pada hakikatnya bersifat subjektif dan menerima pengaruh daripada persekitaran pelajar yang berbeza-beza.

Analisis korelasi pearson dalam kajian ini mendapati bahawa PTK mempunyai hubungan positif yang signifikan dan kuat dengan TKD pelajar. Mudahnya, apabila kadar PTK pelajar meningkat, maka TKD pelajar juga akan meningkat. Dapatan ini konsisten dengan beberapa kajian lepas seperti Raemdonck et al. (2012), Botha et al. (2015) dan Khong (2018) yang telah memperoleh keputusan sama. Kajian ini juga dilihat menyokong kajian beberapa kajian terdahulu yang turut mengkaji hubungan TKD dengan variabel yang berkaitan dengan PTK misalnya tingkah laku pembelajaran sukarela (Kim et al., 2015), kesediaan belajar (Wittekind et al., 2010), serta tingkah laku pembelajaran berkaitan pekerjaan (Gijbels et al., 2010). Justeru, berdasarkan dapatan semasa dan beberapa kajian terdahulu ini, terdapat bukti munasabah bahawa peningkatan keyakinan seseorang pelajar tentang peluang dan kejayaan dalam pasaran buruh selepas menamatkan pengajian adalah berhubungan terus dengan amalan pembelajaran kendiri yang dikuasainya.

Penelusuran lanjut mendapati bahawa kesemua empat faktor PTK (inisiatif, kawalan, efikasi diri, motivasi) juga masing-masing mempunyai hubungan penting dengan TKD pelajar. Dapatan ini menyokong Tymon (2016) yang berhujah bahawa apabila pelajar memiliki tingkah laku proaktif dalam mengawal pembelajaran dan mempunyai inisiatif tinggi untuk merancang, melaksana dan menilai proses pembelajarannya sendiri, maka kebolehan mereka untuk mendepani segala cabaran dalam pasaran buruh dengan efektif juga akan meningkat. Demikian juga, dapatan ini selari dengan Kamaliah et al. (2018) yang berpendapat bahawa pelajar yang memiliki motivasi dan efikasi diri yang tinggi dalam melaksanakan tanggungjawab terhadap pembelajarannya sendiri adalah lebih optimis dan berkeyakinan dalam pasaran buruh.

Satu lagi dapatan penting berjaya dibuktikan dalam kajian ini ialah pengaruh PTK yang signifikan terhadap TKD pelajar. Analisis regresi yang dijalankan mendapati bahawa PTK menyumbang sebanyak 50\% terhadap peningkatan TKD pelajar sekali gus meletakkannya sebagai peramal TKD yang sangat penting. Keputusan ini menjelaskan bahawa keupayaan PTK mampu menguatkan faktor dalaman dan luaran yang begitu penting dalam pembangunan TKD pelajar. Ringkasnya, PTK mampu meramal prospek dan kejayaan pelajar untuk mendapatkan pekerjaan yang sesuai dengan kelayakan selepas menamatkan pengajian dalam pasaran buruh.

Pengaruh PTK terhadap TKD pelajar dalam kajian ini adalah sejajar dengan kajian Botha et al. (2015) yang merumuskan bahawa pelajar yang terarah kendiri diramalkan lebih yakin dengan atribut kebolehgajian yang dimilikinya, malah mereka juga lebih proaktif. Penguasaan serta keyakinan terhadap atribut-atribut kebolehgajian misalnya pengurusan kerjaya diri, keusahawanan, literasi emosi, dan juga proaktif boleh menjamin kejayaan kerjaya seseorang individu. Begitu juga, dapatan kajian ini menyokong kajian Raemdonck et al. (2014) yang merumuskan bahawa individu yang terarah kendiri dalam pembelajaran dijangka akan lebih banyak belajar tentang pekerjaan, yang akan membantunya mendapatkan pengetahuan dan kemahiran sama ada secara langsung mahupun secara tidak langsung. Pengetahuan dan kemahiran inilah yang akan meningkatkan kebolehgajian individu dalam pasaran buruh. 


\section{Implikasi dan Cadangan}

Penyelidikan ini memberikan implikasi dan manfaat sama ada secara langsung dan tidak langsung terhadap teori dan model, penyelidikan dan juga pengamalan khususnya di kolej vokasional. Dari perspektif teori dan model, dapatan kajian ini memberi implikasi dalam menyokong, menjelaskan dan mengembangkan teori atau model yang menghuraikan TKD dan PTK serta perkaitan antaranya. Buktibukti empirikal dalam kajian ini menyokong dan mengesahkan Teori Model Insan dalam pendidikan gagasan Donald et al. (2017) yang mengetengahkan bahawa enam jenis modal insan yang sepatutnya pelajar peroleh melalui pengalaman pendidikan dan pembelajaran di institusi pengajian iaitu modal kemahiran, modal budaya, modal sosial, modal skolastik, modal psikologi (nilai dalaman) dan modal nilai pasaran. Dalam konteks kajian ini, selain menguatkan modal kemahiran, PTK bukan sahaja berperanan meneguhkan modal budaya menerusi elemen media sosial, tetapi juga mengukuhkan modal psikologi atau nilai dalaman pelajar. Modal psikologi menurut Baruch et al. (2005) merangkumi personaliti pelajar yang proaktif, kesedaran diri, keyakinan, harapan, optimisme dan keyakinan diri yang tinggi. Atribut-atribut peribadi dalam modal psikologi ini selari dengan atribut yang dimiliki oleh individu yang memiliki PTK yang tinggi. Selain itu, dapatan kajian ini juga menyumbang kepada kefahaman mengenai beberapa model berkaitan kebolehgajian seperti Model SSPE (Rothwell et al., 2008) dan Model CareerEDGE (DacrePool \& Sewell, 2007) serta model berkaitan PTK seperti Model PRO-SDL (Brockett \& Heimstra, 1991).

Dari aspek penyelidikan, dapatan kajian ini bukan sahaja menyokong, bahkan ia juga mengembangkan dan memperbaharui dapatan-dapatan terdahulu. Oleh itu, penemuan kajian ini boleh dijadikan panduan penyelidikan pada masa akan datang terutamanya dalam mengkaji variabel-variabel yang mempunyai perkaitan dengan PTK dan TKD pelajar. Dalam konteks pendidikan vokasional di Malaysia, kajian ini adalah antara cubaan awal untuk mengkaji hubungan dan pengaruh PTK terhadap TKD pelajar yang sebelum ini lebih kerap dikaji dalam domain pengetahuan berbeza secara berasingan. Justeru, kajian ini memberi implikasi empirikal tentang bagaimana PTK dan TKD saling berkaitan dan bagaimana keduadua konstruk ini boleh dikaji pada masa akan datang. Selain itu, dapatan kajian ini telah memberikan peluang mengesahkan kedua-dua instrumen yang mengukur variabel kajian berdasarkan sampel pelajar vokasional yang setakat ini jarang digunakan. Instrumen Students' Self-Perceived Employability Scale (SSPES) dan Personal Responsibility Orientation of Self-Directed in Learning Scale (PRO-SDLS) yang digunakan dalam kajian ini telah dibuktikan mempunyai kesahan dan kebolehpercayaan yang tinggi. Justeru, instrumen ini boleh digunakan dalam kajian akan datang bergantung kepada kesesuaian objektif.

Selanjutnya, penemuan kajian ini turut memberi implikasi tersendiri terhadap pengamalan terutama sekali dalam kalangan pemegang taruh sektor pendidikan kolej vokasional di Sabah dan Malaysia amnya seperti pensyarah, akademik dan pentadbir kolej, Bahagian Pendidikan Latihan Teknik dan Vokasional (BPLTV), Kementerian Pendidikan Malaysia (KPM), kerajaan dan juga individu pelajar sendiri. Secara umumnya, kajian ini menawarkan cara bagaimana pelajar dapat dipersiapkan untuk memasuki pasaran buruh dengan lebih baik dan membantu meningkatkan kebolehgajian diri pelajar melalui intervensi pembelajaran iaitu PTK. Bukti empirikal kajian ini mendapati bahawa PTK mempunyai hubungan serta pengaruh yang penting terhadap kebolehgajian diri pelajar. Berdasarkan keputusan ini, implikasi dan cadangan terhadap pengalaman adalah bertumpu kepada pedagogi PTK, kurikulum pendidikan, dan juga peluang pembangunan kebolehgajian. Kajian ini menyarankan agar pensyarah serta ahli akademik di kolej vokasional meneruskan usaha mewujudkan suasana pembelajaran yang menggalakkan PTK melalui pemudahcaraan secara aktif, dan pada masa sama berusaha menyemai dan memupuk karakter terarah kendiri dalam kalangan pelajar. Di samping itu, pihak institusi juga perlu memastikan kurikulum program, pelaksanaan pengajaran dan pembelajaran, persekitaran pembelajaran, sokongan dan prasarana pembelajaran adalah tepat kerana elemen ini merupakan pendorong kepada peningkatan PTK, yang seterusnya meningkatkan kebolehgajian pelajar.

Kajian ini juga mencadangkan agar institusi dan pengajar memberi perhatian kepada perkembangan teknologi digital misalnya internet, telefon pintar dan media sosial yang begitu mendominasi masyarakat dunia hari ini. Kebergantungan pelajar terhadap teknologi ini perlu dimanfaatkan sebagai mangkin yang dapat meningkatkan keupayaan PTK mereka. Tambahan pula, penggunaan teknologi digital dan media sosial dalam pendidikan menurut Akgunduz dan Akinoglu (2019) mampu mengubah sikap pelajar tentang pembelajaran dan meningkatkan kemahiran PTK. Justeru, pihak institusi perlu melihat semula polisi- 
polisi yang diamalkan berkaitan penggunaan internet, telefon pintar, dan sebagainya agar secara konsisten dapat menyokong proses PTK dalam kalangan pelajar. Dalam senario pendidikan hari ini, polisi organisasi yang ketat sehingga mengehadkan akses kepada teknologi digital dan mudah alih adalah penghalang kepada pembentukan karakter terarah kendiri dalam kalangan pelajar.

\section{Kesimpulan}

Berdasarkan penemuan kajian, didapati PTK sebagai variabel bebas mempunyai hubungan dan pengaruh langsung yang signifikan terhadap TKD. Keupayaan pelajar melaksanakan pembelajaran terarah kendiri amat penting bagi menentukan tanggapan kebolehgajian diri pelajar. PTK dibuktikan dapat menguatkan faktor dalaman dan luaran pelajar yang menyebabkan mereka lebih berkeyakinan akan memperoleh pekerjaan yang sesuai dengan kelayakan selepas menamatkan pengajian. Jelas bahawa orientasi pembelajaran yang dipupuk menerusi pengalaman pendidikan serta pembelajaran di institusi pengajian memainkan peranan yang cukup penting terutamanya dalam meningkatkan keyakinan pelajar terhadap hala tuju dan prospek mereka dalam pasaran buruh. Dari sudut perkembangan ilmu, kajian ini menyumbang kepada pengetahuan baharu mengenai pembangunan kebolehgajian pelajar melalui intervensi pembelajaran terarah kendiri khususnya dalam konteks kolej vokasional di Sabah dan amnya di Malaysia. Justeru, respons pihak terlibat terhadap penemuan kajian ini adalah penting agar matlamat untuk melahirkan modal insan unggul seperti yang diharap-harapkan dapat dicapai.

Sebagai input kepada cadangan kajian pada masa akan datang, kebolehgajian yang diukur menggunakan persepsi atau tanggapan semata-mata seperti dalam kajian semasa ini sememangnya tidak mendedahkan kebolehgajian sebenar pelajar. Justeru, penyelidik berpendapat adalah lebih menarik untuk melihat kesan PTK terhadap kebolehgajian objektif atau kebolehgajian sebenar selepas pelajar bergraduan dan mendapat pekerjaan sepenuh masa. Untuk itu, penyelidik mencadangkan agar kajian ini boleh diperluaskan kepada kajian longitudinal yang mempertimbangkan kesan masa dan tindak balas. Melalui kajian longitudinal, model hubungan dan pengaruh empirikal antara PTK dengan kebolehgajian pelajar dapat dibentuk dengan lebih baik.

\section{Rujukan}

Akgunduz, D., \& Akinoglu, O. (2016). The effect of blended learning and social media-supported learning on the students' attitude and self-directed learning skills in science education. Turkish Online Journal of Educational Technology, 15(2), 106-115

Bahrim, T. A. I. B. T. K., Azahari, H. I. B. H., Zulkarnal, N. A. A. B., Sallehudin, N. A. B., \& Yusop, R. B. M. (2019). High Rate of Employment Among Graduates in Malaysia. E-JOMS (Malaysian Journal of Media \& Society), 3(July), 1-15.

Baruch, Y., M. P. Bell, \& D. Gray. (2005). "Generalist and Specialist Graduate Business Degrees: Tangible and Intangible Value.” Journal of Vocational Behavior 67 (1), 51-68

Bernston, E. \& Marklund, S. (2007). The Relationship Between Perceived Employability and Subsequent Health. Work \& Stress: An International Journal of Work, Health and Organisations. 21(3). 279292.

Bernston, E., Sverke, M. \& Marklund, S. (2006). Predicting Perceived Employability: Human Capital or Labour Market Opportunities. Economic and Industrial Democracy. 27(2). 223-244.

Botha, J.-A. (2012). The relationship between adult learner self-directedness and employability attributes: an open distance learning perspective. University of South Africa.

Botha, J.-A., Coetzee, M., \& Coetzee, M. (2015). Exploring adult learners' self-directedness in relation to their employability attributes in open distance learning. Journal of Psychology in Africa, 25(1), 6572.

Brockett, R. G. (1983). Self-directed learning and the Hard to Reach Adult. Lifelong Learning: The Adult Years, 6(8), 16-18.

Brockett, R. G., \& Hiemstra, R. (1991). Self-direction in Adult Learning: Perspectives on Theory, Research adn Practices (1st Editio). London: Routledge Taylor \& Francis Group. 
Cheng, C., \& Mohamad, J. (2020). Youth Unemployment in Malaysia \& the Region - ISIS. Japan SPOTLIGHT, Special Ar(February), 49-53

Chou, P.N. (2012). The Development of a Measurement Tool to Assess Chinese Engineering Students' Self-directed learning Abilities. Global Journal of Engineering Education. 142, 196 -199.

Chun, J. (2016). A Multilevel Analysis of the Effects of Individual and Organizational Level Variables on Perceived Employability of Office Workers in Large Corporations Seoul National University, Korea

Coetzee, M., \& Engelbrecht, L. (2019). How Employability Attributes Mediate the Link Between Knowledge Workers' Career Adaptation Concerns and Their Self-Perceived Employability. Psychological Reports, 1-22.

Cohen, L., Manion, L., \& Morrison, K. (2007). Research Methods in Education (6th ed.). United Kingdom: Routledge Publishers

Curran, V., Gustafson, D. L., Simmons, K., Lannon, H., Wang, C., Garmsiri, M., ... Wetsch, L. (2019). Adult learners' perceptions of self-directed learning and digital technology usage in continuing professional education: An update for the digital age. Journal of Adult and Continuing Education, 25(1), 74-93.

Dacre Pool, L., \& Sewell, P. (2007). The key to employability: developing a practical model of graduate employability. Education + Training, 49(4), 277-289.

De Cuyper, N., Bernhard-Oettel, C., Bernston, E., De Witte, H. \& Alarco, B. (2008). Employability and Employees' Well-Being: Mediation by Job Security. Applied Psychology: An International Review. 57(3), $88-509$

Donald, W. E., Baruch, Y., \& Ashleigh, M. (2017). The undergraduate self-perception of employability: human capital, careers advice, and career ownership. Studies in Higher Education, O(0), 1-16.

Emmerik, I.J., Schreurs, B., Cuyper, N.E., Jawahar, I.M. \& Peeters, M. (2012). The Route to Employability: Examining Resources and the Mediating Role of Motivation. Career Development International. 17(2), 104-119

Francom, G.M. (2010). Teach Me How to Learn: Principles for Fostering Students' Self-directed learning Skills. International Journal of Self-directed learning. 7(1), $29-44$

Fugate, M., Kinicki, A. J., \& Ashforth, B. E. (2004). Employability: A psycho-social construct, its dimensions, and applications. Journal of Vocational Behavior, 65(1), 14-38.

Gijbels, D., Raemdonck, I. \& Vevecken, D. (2010). Influencing Work-Related Learning: The Role of Job Characteristics and Self-Directed Leaning Orientation in Part-Time Vocational Education. Vocations and Learning. 3. pp. 239-255.

Guilbert, L., Bernaud, J., Gouvernet, B. \& Rossier, J. (2016). Employability: Review and Research Prospects. International Journal of Educational and Vocational Guidance. 16, 69 -89

Huang, J.T. 2015. Hardiness, Perceived Employability, and Career Decision Self-Efficacy Among Taiwanese College Students. Journal of Career Development. 42(4), 311-324

Ibrahim, D. H. M., \& Mahyuddin, M. Z. (2017). Youth Unemployment in Malaysia: Developments and Policy Considerations. Bank Negara Malaysia Outlook and Policy Report 2017.

ILO (2016). World Employment and Social Outlook. 2015. International labor office, Geneva

Jabatan Perangkaan Malaysia. (2018). BULETIN PERANGKAAN BULANAN MALAYSIA. Retrieved from https://www.dosm.gov.my

Kamaliah, S., Roslan, S., Bakar, A. R., \& Ghiami, Z. (2018). The effect of supervised work experience on the acquisition of employability skills among Malaysian students. Higher Education, Skills and Work-Based Learning, 8(4), 354-364

Kassim, Z. B. A. (2020). Dilema Isu Pengangguran Belia Di Malaysia. Institut Maklumat Dan Analisis Pasaran Buruh, Kementerian Sumber Manusia (ILMIA), AR/3.2020.Kementerian Pendidikan Malaysia (KPM). (2018). Laporan Pengesanan Graduan 2017. Putra. Retrieved from www.moe.gov.my

Kementerian Pendidikan Malaysia (KPM). (2019). Laporan Pengesanan Graduan 2018. Putrajaya. Retrieved from www.moe.gov.my

Kementerian Pendidikan Tinggi Malaysia. (2018). Kajian Pengesanan Graduan 2017. Retrieved from http://www.mohe.gov.my/muat-turun/awam/statistik/2017

Khong, C. S. (2018). The Relationship between Self-Directedness in Learning and Employability : A study at a Private University in Dubai, United Arab Emirates. University of Leicester.

Kim, H. Y., \& Kim, G. U. (2018). The Effect of Self-Directedness in Learing on Employment Readiness of Undergraduates in South Korea. Journal of Education and Learning, 7(3), 125. 
Kidane, H. H., Roebertsen, H., \& Van Der Vleuten, C. P. M. (2020). Students' perceptions towards selfdirected learning in Ethiopian medical schools with new innovative curriculum: A mixed-method study. BMC Medical Education, 20(1), 1-10.

Kim, S.J., Kim, H.S., \& Lee, J.K. (2015). Employee self-concepts, voluntary learning behavior, and perceived employability. Journal of Managerial Psychology. 30(3), 264-279.

Knowles, M. S. (1975). Self-Directed Learning: A Guide for Learners and Teachers. New York: The Adult Education Company.

Krejcie, R. V, \& Morgan, D. (1970). DETERMINING SAMPLE SIZE FOR RESEARCH ACTIVITIES. Educational and Psychological Measurement, 30, 607-610.

Law, C. S. 2018. Malaysia Public Universities' Graduate Employability Policies : An Analysis of First Degree Graduates Unemployment and Underemployment Issues. International Journal of Social Science and Humanities Research, 6(4), 480-489

Lee, K. S., Tsai, P. S., Chai, C. S., \& Koh, J. H. L. (2014). Students' perceptions of self-directed learning and collaborative learning with and without technology. Journal of Computer Assisted Learning, $30(5), 425-437$.

Leo, M. (2018). What You Didn't Know About Fresh Graduate Unemployment in Malaysia [Infographic]. Retrieved from https://eduadvisor.my/articles/what-didnt-know-fresh-graduate-unemploymentmalaysia-infographic/

Lo Presti, A., \& Pluviano, S. (2016). Looking for a route in turbulent waters: Employability as a compass for career success. Organizational Psychology Review, 6(2), 192-211.

Magnano, P., Santisi, G., Zammitti, A., Zarbo, R., \& Nuovo, S. Di. (2019). Self-perceived employability and meaningful work: The mediating role of courage on quality of life. Sustainability (Switzerland), 11(764), 1-14.

O'Donoghue, J. dan Maguire, T. (2005). The Individual Learner, Employability and the Workplace: A Reappraisal of Relationships and Prophecies. Journal of European Industrial Training. 29(6), 436446.

Premkumar, K., Vinod, E., Sathishkumar, S., Pulimood, A. B., Umaefulam, V., Prasanna Samuel, P., \& John, T. A. (2018). Self-directed learning readiness of Indian medical students: A mixed method study. BMC Medical Education, 18(1), 1-10.

Qenani, E., MacDougall, N., \& Sexton, C. (2014). An empirical study of self-perceived employability: Improving the prospects for student employment success in an uncertain environment. Active Learning in Higher Education, 15(3), 199-213.

Ramsey, V.J. \& Couch, P.D. (1994). Beyond Self-directed learning: a Partnership Model of Teaching and Learning. Journal of Management Education. 18(2), 139-162

Raemdonck, I., Gijbels, D., \& Van Groen, W. (2014). The influence of job characteristics and self-directed learning orientation on workplace learning. International Journal of Training and Development, 18(3), 188-203.

Raemdonck, I., Van Der Leeden, R., Valcke, M., Segers, M., \& Thijssen, J. (2012). Predictors of Selfdirected learning for Low-Qualified Employees: A Multi-Level Analysis. European Journal of Training and Development. 36(6). pp. 572-591.

Rashid, T., \& Asghar, H. M. (2016). Technology use, self-directed learning, student engagement and academic performance: Examining the interrelations. Computers in Human Behavior, 63, 604-612.

Roskies, E. \& Louis-Guerin, C. (1990). Job Insecurity in Managers: Antecedents and Consequences. Journal of Organizational Behavior. 11. pp. 345-359.

Rothwell, A., Herbert, I., \& Rothwell, F. (2008). Self-perceived employability: Construction and initial validation of a scale for university students. Journal of Vocational Behavior, 73(1), 1-12.

Stockdale, S. L., \& Brockett, R. G. (2011). Development of the PRO-SDLS : A Measure of Self- Direction in Learning Based on the Personal Responsibility Orientation Model. Adult Education Quartely, 61(2), 161-180.

Sulasiwi, I. F., Handayanto, S. K., \& Wartono, W. (2019). Eksplorasi keterampilan self-directed learning (SDL) siswa SMA: a descriptive research study. Momentum: Physics Education Journal, 3(1), 4252.

Taqipour, M., Abbasi, E., Naeimi, A., Ganguly, S., \& Miandasthi, N. Z. (2016). An investigation of selfdirected learning skills among the Iranian agricultural students (Case of agricultural college, tarbiat modares university). Journal of Agricultural Science and Technology, 18(1), 15-26

Taat, M. S., \& Abdullah, M. Y. (2014). Impak Pengajaran Dan Bimbingan Guru Pendidikan Islam 
Terhadap Motivasi Dan Pembelajaran Terarah Kendiri Pelajar. Jurnal Pemikir Pendidikan (Joumal for Educational Thinkers), 5, 1-17.

Thijssen, J.G.L, Van der Heijden, B. \& Rocco, T.S. (2008). Toward the Employability-Link Model: Current Employment Transition to Future Employment Perspectives. Human Resource Development Review. 7(2), 165-183.

Tohidi, S. (2019). The Relationship between Self-Directed Learning and Motive of Progress and Learning Strategies in Students of Hamedan University of Medical Sciences. Journal of Medical Education, $18(1)$.

Tymon, A. (2013). Studies in Higher Education The student perspective on employability. Studies in Higher Education, 38(6), 841-856.

Veld, M., Semejin, J. \& Van Vuuren, T. (2015). Enhancing Perceived Employability: An Interactionist Perspective on Responsibilities of Organizations and Employees. Personnel Review. 44(6), 866 882.

Wittekind, A., Raeder, S., \& Grote, G. (2010). A longitudinal study of determinants of perceived employability. Journal of Organizational Behaviour, 31, 566-586.

Yusof, Nooriah, \& Jamaluddin, Z. (2015). Graduate employability and preparedness : A case study of University of Malaysia Perlis (UNIMAP ), Malaysia. Malaysian Journal of Society and Space, 11(11), 129-143.

Zaliza, H, \& Safarin, N. M (2014). Unemployment Among Malaysia Graduates:Graduates' Attributes, Lecturers' Competency and Quality of Education. Procedia - Social and Behavioral Sciences, 112 (Iceepsy 2013), 1056-1063. 